\title{
Peroral Endoscopic Myotomy for Treating Achalasia and Esophageal Motility Disorders
}

\author{
Young Hoon Youn, ${ }^{1}$ Hitomi Minami, ${ }^{2}$ Philip Wai Yan Chiu, ${ }^{3 *}$ and Hyojin Park ${ }^{1 *}$ \\ ${ }^{I}$ Department of Internal Medicine, Gangnam Severance Hospital, Yonsei University College of Medicine, Seoul, Korea; ${ }^{2}$ Department of \\ Gastroenterology and Hepatology, Nagasaki University Hospital, Nagasaki, Japan; and ${ }^{3}$ Institute of Digestive Disease, The Chinese University of \\ Hong Kong, Shatin, Hong Kong
}

Peroral endoscopic myotomy (POEM) is the application of esophageal myotomy to the concept of natural orifice transluminal surgery (NOTES) by utilizing a submucosal tunneling method. Since the first case of POEM was performed for treating achalasia in Japan in 2008, this procedure is being more widely used by many skillful endosopists all over the world. Currently, POEM is a spotlighted, emerging treatment option for achalasia, and the indications for POEM are expanding to include long-standing, sigmoid shaped esophagus in achalasia, even previously failed endoscopic treatment or surgical myotomy, and other spastic esophageal motility disorders. Accumulating data about POEM demonstrate excellent short-term outcomes with minimal risk of major adverse events, and some existing long-term data show the efficacy of POEM to be long lasting. In this review article, we review the technical details and clinical outcomes of POEM, and discuss some considerations of POEM in special situations.

(J Neurogastroenterol Motil 2016;22:14-24)

Key Words

Achalasia; Myotomy; Peroral endoscopic myotomy; Treatment

\section{Backgrounds}

\section{Achalasia and the History of Peroral Endoscopic Myotomy}

Surgical myotomy has been the most reliable treatment of choice for treating esophageal achalasia since the first report by
Heller in 1913. ${ }^{1}$ Other management methods include medication, balloon dilatation, ${ }^{2,3}$ and botulinum toxin injection, ${ }^{4,5}$ which are still inconclusive because of the relatively low efficacy and also relatively high complication rates.

The concept of natural orifice transluminal endoscopic surgery (NOTES) was introduced by Kalloo and his colleagues. ${ }^{6,7}$ Under the influence of the rapidly increasing demands for less-invasive treatment, Inoue et $\mathrm{al}^{8}$ introduced peroral endoscopic myotomy

Received: December 1, 2015 Revised: December 14, 2015 Accepted: December 22, 2015

(a) This is an Open Access article distributed under the terms of the Creative Commons Attribution Non-Commercial License (http://creativecommons. org/licenses/by-nc/4.0) which permits unrestricted non-commercial use, distribution, and reproduction in any medium, provided the original work is properly cited.

*Correspondence: Philip Wai Yan Chiu and Hyojin Park are equally responsible for this study. Philip Wai Yan Chiu, MD, FRCSEd Institute of Digestive Disease, The Chinese University of Hong Kong, Hong Kong Tel: +852-2632-2627, Fax: +852-2632-7974, E-mail: philipchiu@surgery.cuhk.edu.hk Hyojin Park, MD, PhD

Department of Internal Medicine, Gangnam Severance Hospital, Yonsei University Medical College, 211 Eonjuro, Gangnam-gu, Seoul 06273, Korea

Tel: +82-2-2019-3318, Fax: +82-2-3463-3882, E-mail: hjpark21@yuhs.ac

Young Hoon Youn and Hitomi Minami contributed equally to this review article. 
Table 1. Characteristics of Peroral Endoscopic Myotomy Compared with Laparoscopic Heller Myotomy and Pneumatic Dilation

\begin{tabular}{|c|c|c|c|}
\hline & POEM & LHM & $\mathrm{PD}$ \\
\hline Scarring & No & Yes & No \\
\hline Selective circular myotomy & Possible & No & No \\
\hline Concurrent anti-reflux procedure & No & Fundoplication & No \\
\hline Dissection and disruption of the diaphragmatic hiatus & No & Yes & No \\
\hline \multirow[t]{2}{*}{ Postoperative incidence of GERD } & $(+++)$ & $(++)$ & $(+/-)$ \\
\hline & $\begin{array}{l}\text { Symptomatic GERD } \\
\text { approximately } 20-30 \%\end{array}$ & $\begin{array}{l}\text { Symptomatic GERD } \\
\text { approximately } 15 \%\end{array}$ & \\
\hline Myotomy extension to the proximal esophageal body & Possible & Difficult & Impossible \\
\hline Hospital stay & Intermediate & Relatively long & Very short \\
\hline Cost & $\begin{array}{l}\text { Intermediate (variable } \\
\text { according to region) }\end{array}$ & High & Low \\
\hline Clinical response for achalasia & Good (excellent) & Good & Fair \\
\hline Clinical response for spastic esophageal disorders & Good & Fair & Poor \\
\hline
\end{tabular}

POEM, peroral endoscopic myotomy; LHM, laparoscopic Heller myotomy; PD, pneumatic dilation; GERD, gastroesophageal reflux disease.

(POEM) in humans as a non-surgical treatment method for esophageal achalasia in 2010. Since then, POEM has been one of the standard treatments for treating esophageal achalasia and related esophageal motility diseases, such as diffuse esophageal spasm and jackhammer esophagus. ${ }^{8-10}$

Table 1 summarizes the general characteristics of POEM compared with laparoscopic Heller myotomy and pneumatic dilation.

\section{Procedure of Peroral Endoscopic Myotomy -}

\section{Indications}

The indications for POEM encompass the conditions that are responsible for the excessive behavior of the inner circular muscle layer. Unlike other options, POEM theoretically allows myotomy to be performed for muscles of any length, position, and direction because of its intraluminal route of approach. Therefore, esophageal achalasia is the most cardinal indication. Furthermore, diffuse esophageal spasm (distal esophageal spasm, DES), jackhammer esophagus, and surgically failed cases, all of which require flexible myotomy depending on the condition in each case, can also be recommended indications. ${ }^{11}$ Moreover, POEM may be the only option for surgically failed cases because surgical re-do myotomy is extremely difficult due to the fibrosis and scarring as a result of previous surgery.

\section{Pre-operative Evaluation}

Esophagogastroduodenoscopy (EGD), barium swallow, and manometry should be performed preoperatively in order to confirm the diagnosis and the treatment strategy. Evaluation of the shape of the esophagus, disease progression grade, and dynamic observation of the esophagus is mandatory to comprehend the pathology of the disease.

EGD enables us to assess the width of the esophagus, the amount of the esophageal contents, and abnormal movement of the esophageal body. EGD is also requisite to rule out pseudoachalasia; computed tomography or endoscopic ultrasound is also required to rule out submucosal cancer in the esophagus/gastric cardia, or extrinsic compression due to lymph node swelling or tumors of the adjacent structures. ${ }^{12}$ Because achalasia is a high-risk factor of esophageal cancer, direct visualization of the mucosal surface is quite important in order to detect the early signs of esophageal cancer.

According to the shape of the esophagus, achalasia patients are classified as having the straight or sigmoid type with severe tortuosity. The maximum diameter of the thoracic esophagus is also measured. Barium esophagogram allows us to visualize important information about the dynamics of the esophagus, such as the site of abnormal contraction, simultaneous contraction, and barium accumulation. Timed barium esophagogram (TBE) measures the distance from the distal esophagus to the top of a distinct retained barium column (barium height) and the maximal esophageal width (barium width) at 1,2, and 5 minutes after barium ingestion. TBE is a noninvasive and effective method in both the diagnosis and evaluation of response to treatment of achalasia.

Esophageal manometry is another essential examination suitable for the evaluation of detailed esophageal function. The Chicago classification of esophageal motility was developed by Bredenoord et $\mathrm{al}^{13}$ who interpreted the results of clinical high-resolution ma- 
nometry (HRM) studies. The latest version of the classification was released in 2015, considering the updating technology and clinical practice. $^{14}$

\section{Prerequisites}

Patients are admitted on the day before POEM and were asked to fast (no solid food) for 24 hours before the procedure. EGD is performed before the administration of general anesthesia in order to remove the food remnants from the esophagus prior to intubation. Patients are asked to lie in the supine position. Administration of broad-spectrum intravenous antibiotics is started before POEM for prevention of infection.

A forward-viewing endoscope is used with a transparent distal cap attachment (DH-28GR, FTS). A triangle tip knife (KD640L; Olympus) or possibly other endoscopic knives can be used to dissect the submucosal layer and to divide circular muscle bundles. A coagulating forceps (Coagrasper, FD-411QR; Olympus) is used for vessel coagulation of larger vessels prior to dissection and for hemostasis. An electrogenerator, VIO 300D (ERBE, Tubingen, Germany) is utilized. In addition, hemostatic clips (EZ-CLIP, HX-
110QR; Olympus) are applied for the final closure of the mucosal entry site. The procedures are performed with the patient under general anesthesia with positive pressure ventilation. The UCR $\mathrm{CO}_{2}$ insufflator (Olympus) is used with a regular insufflating tube (MAJ-1742; Olympus), which maintains continuous $\mathrm{CO}_{2}$ insufflation at a constant rate of 1.2 liter/minute.

\section{Precise Operative Steps}

The POEM procedure is performed as follows:

1. Approximately $10 \mathrm{~mL}$ saline supplemented with $0.3 \%$ indigo carmine is injected into the submucosal space on the anterior (11-2 o'clock) or posterior (5 o'clock) wall of the mid-esophagus. Subsequently, a 2-cm longitudinal mucosal incision is made as a mucosal entry into the submucosal space (the dry cut mode [50 W, effect 3], or the Endocut I mode) (Fig. 1). Then, a technique similar to endoscopic submucosal dissection is used to create a submucosal tunnel approximately 2 or $3 \mathrm{~cm}$ into the proximal stomach (Fig. 2). The spray coagulation mode (40-60 W, effect 1-2) is used to dissect the submucosal layer. Larger vessels in the submu-

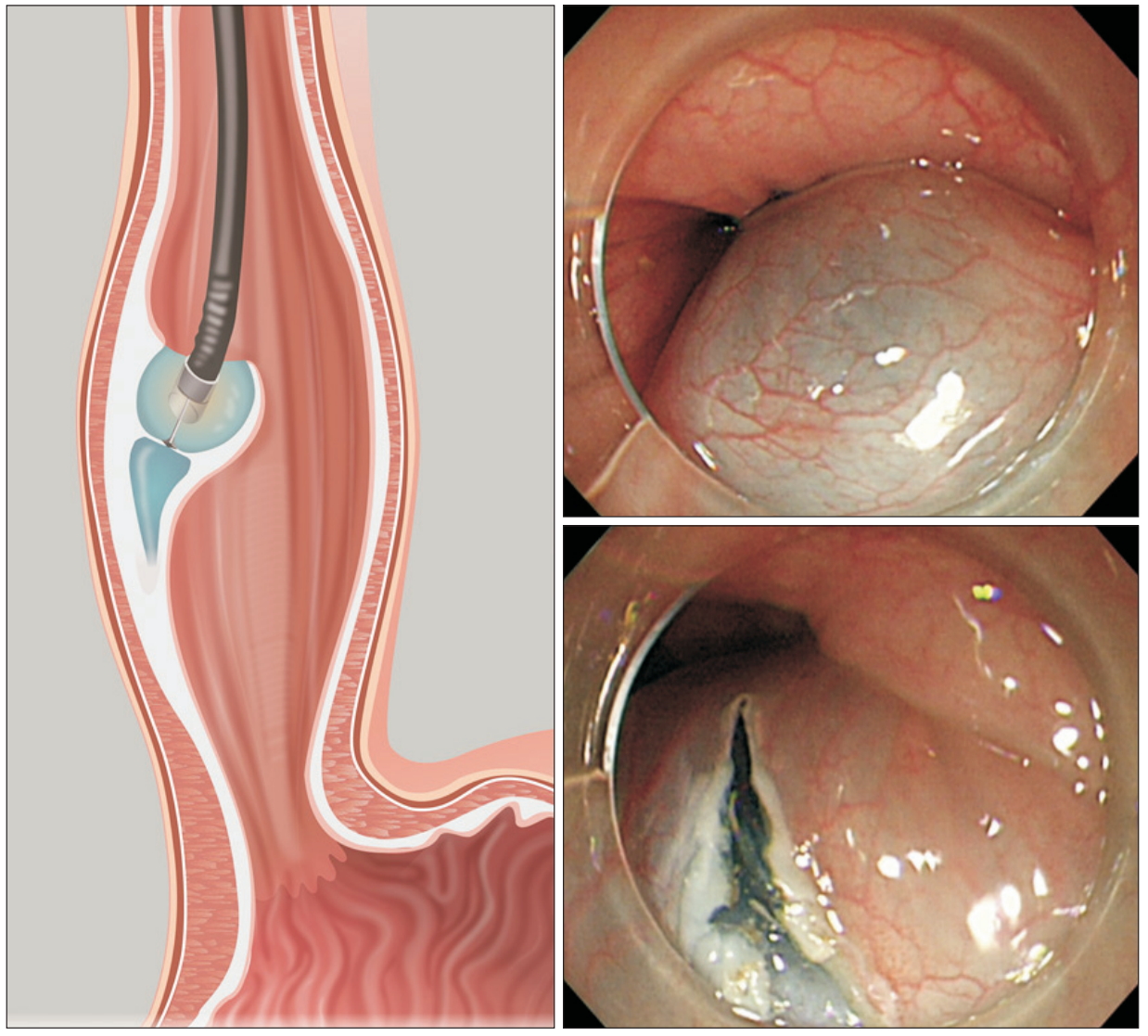

Figure 1. Entry to the submucosal space. After submucosal injection of saline and $0.3 \%$ indigo carmine mixture, a $2-\mathrm{cm}$ longitudinal mucosal incision is made at the mid esophagus. 

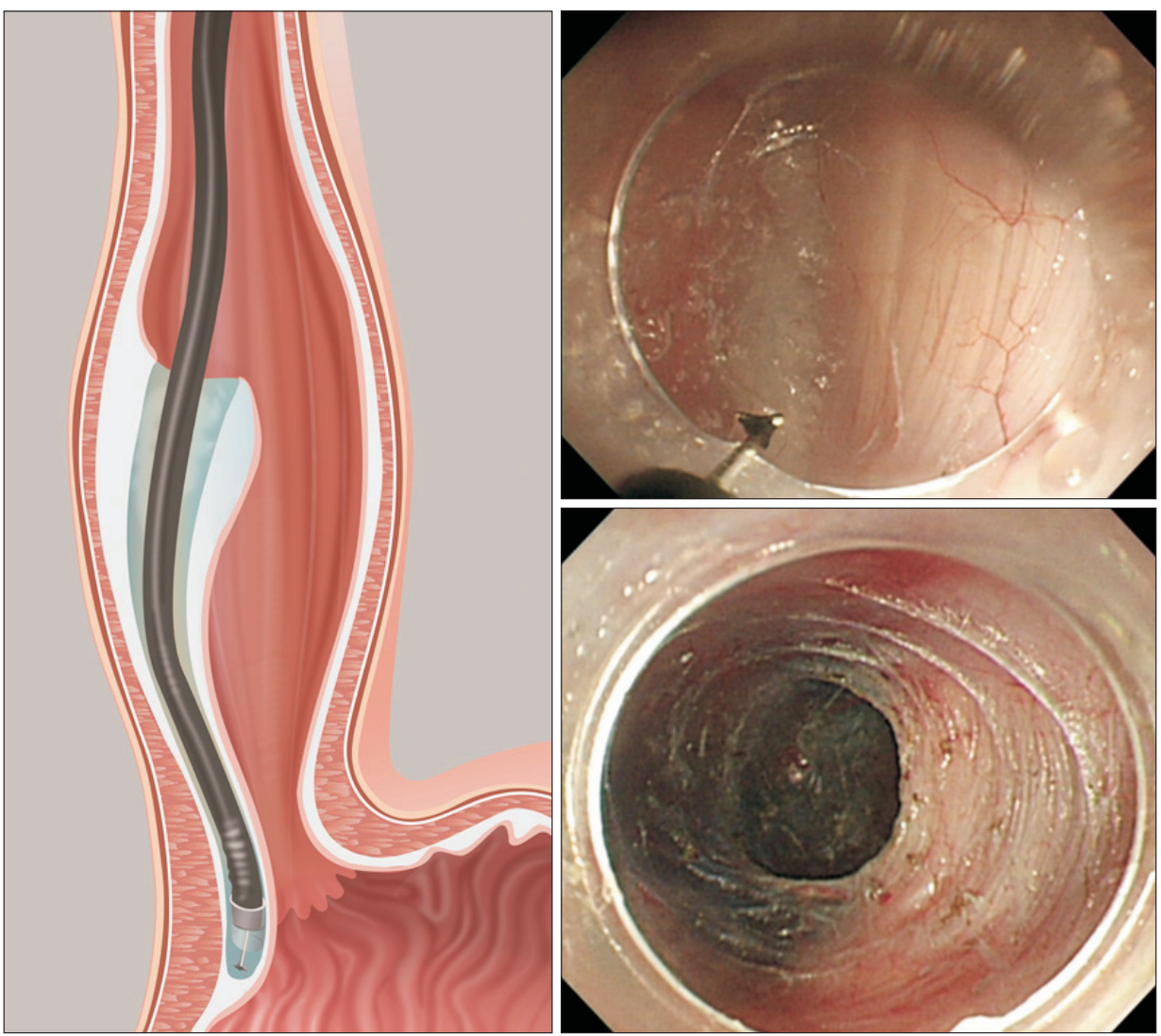

Figure 2. Submucosal tunneling. A long submucosal tunnel is created $2-3 \mathrm{~cm}$ distal to the esophagogastric junction. The circular muscle fibers are perpendicular to the longitudinal direction of the tunnel. cosa are coagulated using the forceps in the soft coagulation mode $(80 \mathrm{~W}$, effect 5$)$. The determination of anterior (11-2 o'clock) or posterior (5 o'clock) position of submucosal tunneling and myotomy is up to the preference of the operator. Although there is few evidence, many experts suggest that posterior myotomy may have an advantage for relief of dysphagia, and anterior myotomy may be better in the prevention of gastroesophageal reflux disease.

2. Dissection of the circular muscle bundle is started at $2-3 \mathrm{~cm}$ distal from the mucosal entry by using a triangle tip knife (Fig. 3). The captured circular muscle is cut by using a spray coagulation current (40-60 W, effect 1-2), avoiding massive bleeding from the intra-muscular vessels. Division of the sphincter muscle is continued from the proximal side towards the stomach and 2 or $3 \mathrm{~cm}$ into the cardia (Fig. 3), according to the surgical standards of Heller myotomy. The esophagogastric junction (EGJ) is identified by recognizing one or more of the following: (1) the narrow segment of the esophageal lumen at the lower esophageal sphincter (LES) and opening in the stomach, (2) change of the vascular pattern and palisade vessels that were identified when dissect- ing the tunnel, as well as irregularly arranged vessels in the gastric cardia, (3) tattooing with indocyanine green by recognizing the color of indocyanine green injected prior to myotomy, ${ }^{15}$ and (4) double scope technique in which a second endoscope is used to obtain a retroflexed view of the gastric cardia, while the dissecting scope transilluminate from the end of the submucosal tunnel. ${ }^{16}$

3. After completion of the myotomy, improvement of the endoscope passage at the EGJ is confirmed from inside the tunnel and the true esophageal lumen. The incised mucosal entry is closed with hemostatic clips after prophylactic antibiotic solution spraying inside the tunnel. Complete closure of the mucosal entry is confirmed endoscopically (Fig. 4).

\section{Postoperative Care}

Oral intake of clear water is started after the esophagogram or EGD confirms the smooth passage of a contrast agent without leakage and absence of ischemic/hemorrhagic color change of the mucosa. On post-operative day 2, a soft diet is started. The use of intravenous antibiotics is discontinued 3 days after the procedure; antibiotics were switched to oral intake for another 7 days. 


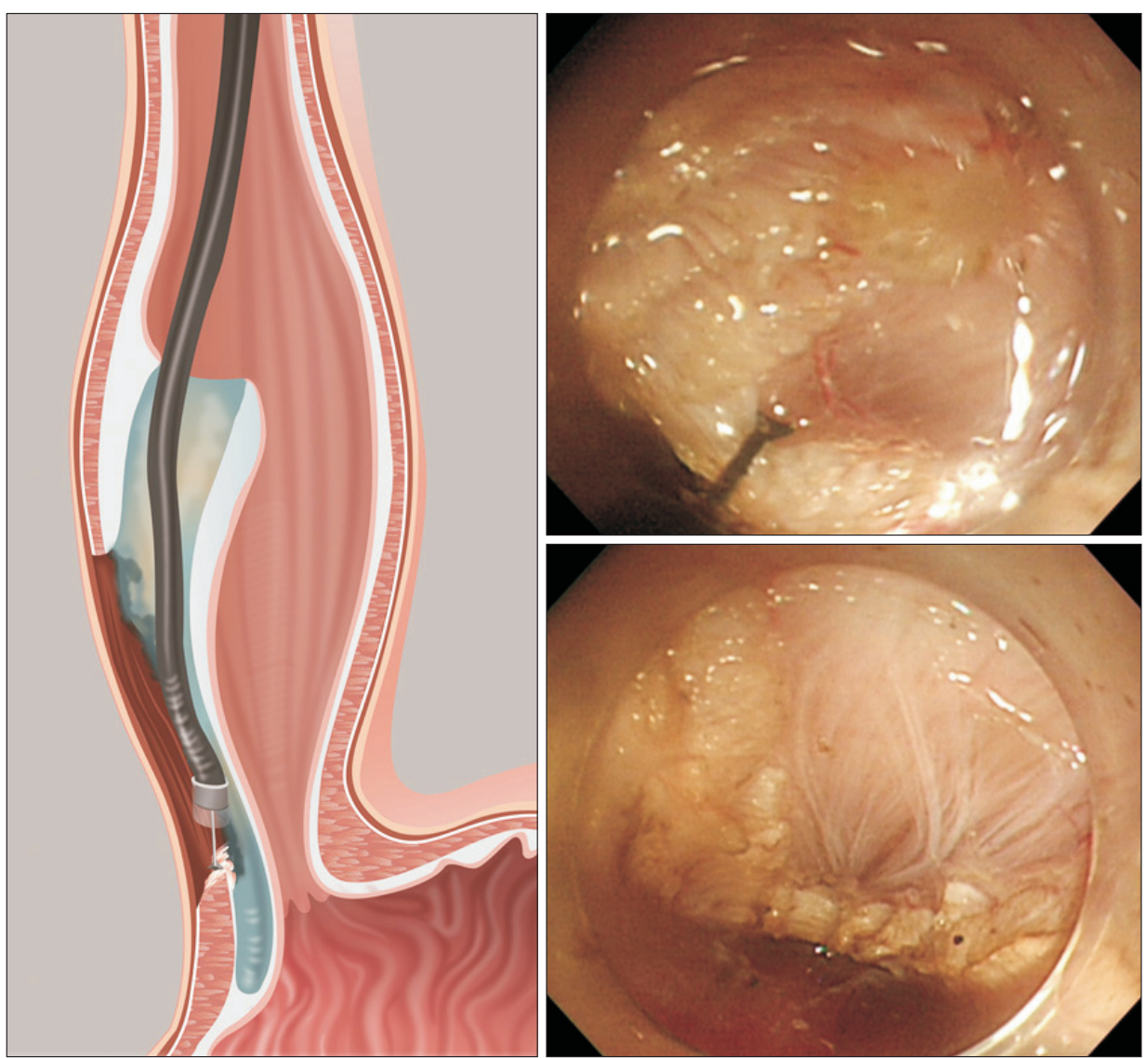

Figure 3. Endoscopic myotomy of circular muscle bundle begins from $2-3 \mathrm{~cm}$ distal to the mucosal entry and extends to $2-3 \mathrm{~cm}$ distal to the esophagogastric junction. By using a triangle tip knife, endoscopic myotomy of inner circular muscle bundles is done, leaving the outer longitudinal muscle layer intact.
The functional evaluations including TBE, manometry and pH-metry as well as endoscopy are repeated 3-6 months after POEM in order to elucidate the effect of the procedure, complications, and changes to esophageal motility. ${ }^{17}$

\section{Outcomes of Peroral Endoscopic Myotomy -}

\section{Short-term Outcomes}

Because POEM is a treatment option for symptomatic achalasia or esophageal motility disorders, the most important measure in evaluating the clinical efficacy of POEM should be subjective symptoms. Most clinical series of POEM report pre- and postPOEM Eckhart's score as a subjective measure of treatment efficacy, and mostly define clinical success as a post-POEM Eckhart's score of $<3$. The short-term clinical success of POEM was reported to be $82 \%$ to $100 \%$ until 12 months, mostly $>90 \%$, which is highly effective. Some studies also investigated the quality of life before and after POEM by using a standardized questionnaire, and showed that POEM provided significant improvement in the quality of life. $^{24-27}$

For objective measurements of efficacy, various parameters can be compared before and after the treatment of achalasia. The objective parameters include barium column height in timed barium esophagograms (TBE), ${ }^{28,29}$ LES pressure, integrated relaxation pressure, ${ }^{30}$ and GE junction distensibility as measured by EndoFLIP (Endolumenal Functional Lumen Imaging Probe; Crospon, Galway, Ireland). ${ }^{31}$ Many studies regarding POEM reported not only subjective clinical symptomatic success, but also objective assessment. POEM has also demonstrated a significant reduction of TBE column height, LES pressure, and integrated relaxation pressure in most cases. ${ }^{19,26,32}$ EndoFLIP provides a quantitative assessment of luminal patency and sphincter distension, and recently has been increasingly reported as a method of assessing the adequacy of myotomy. EGJ distensibility measurements on EndoFLIP have been shown to correlate better with postoperative symptoms compared to manometric pressure measurements. ${ }^{33}$ Intraprocedural application of EndoFLIP to POEM was highly predictive of postoperative symptomatic outcomes. ${ }^{34,35}$

Along with the improvement of manometric profiles of EGJ, 



Figure 4. Closure of the mucosal entry. The mucosal incision of entry point is completely closed with hemostatic clips.

some patients also experienced recovery of esophageal body peristalsis after treatment of achalasia. There have been a few reports of recovery of esophageal body peristalsis after POEM for achalasia. Forty-seven percent of patients had partial recovery of peristalsis in an early European multicenter series of POEM, ${ }^{19}$ and $36 \%$ of achalasia patients in another single-center study showed some return of normal peristalsis ( $\geq 70 \%$ peristalsis) on post-operative HRM. ${ }^{36}$ However, esophageal body peristalsis does not seem to be consistently affected. Another recently published study demonstrated that only 2 of 66 patients had some degree of antegrade peristalsis after POEM. ${ }^{37}$ Further study is needed to clarify the recovery of esophageal body peristalsis after POEM.

\section{Long-term Outcomes}

Long-term follow-up data after POEM are accumulating over time. A representative long-term follow-up study is the one performed by Inoue et al, ${ }^{38}$ who reported the outcomes of 500 consecutive patients treated with POEM with a follow-up of more than 3 years. They showed that 2-month, 1- to 2-year, and 3-year overall success rates were $91.3 \%, 91.0 \%$, and $88.5 \%$, respectively. ${ }^{38}$ Table 2 summarizes the findings of seven recently published studies that report the long-term outcomes of POEM after a follow-up of more than 1 year. ${ }^{19,36,38-42}$ Most of these series demonstrated a sustained clinical success of POEM in $>90 \%$ of patients, with the follow-up duration ranging from 12 months to $>36$ months. ${ }^{19,36,38-42}$ However, one international prospective multicenter study showed some decline in clinical success over time. ${ }^{39}$ Von Renteln et $\mathrm{al}^{39}$ demonstrated a $97 \%$ treatment success at 3 months, $88.5 \%$ at 6 months, and $82.4 \%$ at 12 months, which significantly declined from the initial treatment success. Although we cannot determine the exact reason of such a decline in the efficacy in this trial, one can suppose that it is probably due to the multicenter nature of this trial conducted in the relatively early stage of the POEM era, because of the variability in experience and performance of the operators.

To summarize, the literature to date supports the notion that the high efficacy of POEM generally seems to be durable and long lasting.

\section{Complications of Peroral Endoscopic Myotomy}

As reported, the POEM procedure can be described as a sur- 
Table 2. Long-term Efficacy of Peroral Endoscopic Myotomy (Data from Published Studies in the Order of a Long Follow-up Duration)

\begin{tabular}{|c|c|c|c|c|c|c|}
\hline & $\begin{array}{c}\text { Total subject } \\
\text { number }\end{array}$ & $\begin{array}{l}\text { Follow-up } \\
\text { (months) }\end{array}$ & $\begin{array}{l}\text { Clinical } \\
\text { success }\end{array}$ & $\begin{array}{l}\text { Eckardt score } \\
\text { (before/after) }\end{array}$ & $\begin{array}{l}\text { LES pressure } \\
(\mathrm{mmHg}) \\
\text { (before/after) }\end{array}$ & $\begin{array}{c}\text { Clinical GERD } \\
\text { (symptomatic } \\
\text { or PPI use) }\end{array}$ \\
\hline Inoue et $\mathrm{al}^{38}$ & 500 & Over 36 & $\begin{array}{r}88.5 \% \\
(54 / 61)\end{array}$ & $6.0 / 1.7$ & $28.7 / 14.0$ & $21.3 \%$ \\
\hline Hu et $\mathrm{al}^{40}$ & 32 (Sigmoid type) & 30 (median) & $96.8 \%$ & $7.8 / 1.4$ & $37.9 / 12.9$ & $25.8 \%$ \\
\hline Chen et $\mathrm{al}^{41}$ & 26 (pediatric patients) & 24.6 (mean) & $100 \%$ & $8.3 / 0.7$ & $31.6 / 12.9$ & $19.2 \%$ \\
\hline Sharata et $\mathrm{al}^{36}$ & 75 & 20.1 (mean) & $97 \%$ & $6 / 1$ & $22.2 / 11.7$ & $19.1 \%$ \\
\hline Minami et $\mathrm{al}^{42}$ & 28 & 16 (median) & $100 \%$ & $6.7 / 0.7$ & $71.2 / 21$ & $21.4 \%$ \\
\hline Teitelbaum et $\mathrm{al}^{19}$ & 41 & 15 months (median) & $92 \%$ & $7 / 1$ & $28 / 11$ & $15 \%$ \\
\hline Von Renteln et $\mathrm{al}^{39}$ & 70 & 12 (median) & $82.4 \%$ & $6.9 / 1$ & $27.6 / 8.9$ & $29 \%$ \\
\hline
\end{tabular}

LES, lower esophageal sphincter; GERD, gastroesophageal reflux disease; PPI, proton pump inhibitor.

gical myotomy that is done in an endoscopic manner. Therefore, minor pneumomediastinum or pneumoperitoneum with minimum effects on perioperative course are not considered complications.

So far, there have been considerably many studies regarding POEM against esophageal achalasia, with more than 1000 cases after introduction of the technique. Zhong and his colleagues collected data about complications from their 119 cases in $2012 .^{43}$ Complications related to gas insufflation such as cutaneous emphysema, pneumothorax, and pneumoperitoneum occurred in more than half of all the patients (subcutaneous emphysema [55.5\%, $66 / 119]$, pneumothorax [2.5\%, 3/119], and pneumoperitoneum $[39.5 \%, 47 / 119])$. The use of $\mathrm{CO}_{2}$ as an insufflating gas and general anesthesia with positive ventilation is necessary to avoid these complications. They mentioned that the incidence of these complications significantly reduced after they started to use $\mathrm{CO}_{2}$ as an insufflating gas.

They also reported that delayed hemorrhage occurred in 1 patient. The patient recovered after conservative management after the blood clot was removed from the submucosal tunnel lumen by gastroscopy. Severe mediastinitis is another important post-operative complication. There have been also some reports of mediastinal leakage due to esophageal perforation, which needed thoracoscopic or laparoscopic drainage and extended hospital stay. ${ }^{20,27,44}$ Complete and precise closure of the entry site and careful observation after starting solid foods are important to avoid this unfavorable complication.

In a recent literature published by Inoue and his colleagues, the incidence of adverse events related to the POEM procedure was $<$ $3.2 \%$, including 1 case of pneumothorax, 1 case of severe bleeding, 3 cases of post-operative hematomas, and 1 case of local peritonitis. All patients with these complications recovered with conservative treatment, and no procedure-related deaths were reported. ${ }^{38}$

\section{Peroral Endoscopic Myotomy in Special Situations}

\section{Pediatric Patients}

One of the concerns regarding POEM would be the feasibility of this procedure in extremely young patients. However, there have been several case reports of successful POEM even in infants, resulting in a good clinical response without specific complications. $^{45,46}$ In a recent relatively large series of POEM in 27 children with achalasia, the authors reported that a total of 26 patients $(96.3 \%)$ underwent successful POEM. Submucosal tunneling failed in 1 patient because of serious inflammation and adhesion. Among the 26 children who received successful POEM, the clinical treatment success was maintained in all during a mean follow-up period of 24.6 months (range 15-38 months), and no serious adverse events related to POEM were encountered. ${ }^{41}$ These data suggest that the efficacy and safety of POEM in pediatric achalasia patients are also promising, similar to those in adult patients.

\section{Previous Endoscopic and Surgical Treatment}

There can be some concerns about the feasibility, safety, and efficacy of POEM in patients who have undergone previous endoscopic (botulinum toxin injections or pneumatic balloon dilation) or surgical treatment. Previous intervention at the EGJ may result in some degree of submucosal fibrosis that hinders safe submucosal tunneling through the EGJ. Previous interventions may possibly make the POEM procedure more difficult compared to that in treatment naïve patients. 
Regarding previous endoscopic treatment, a study prospectively compared the POEM procedure in 30 naïve patients, with 21 patients who had undergone previous pneumatic dilation. ${ }^{47}$ This study showed a significantly longer operation time in the patients with previous pneumatic dilations; however, the outcomes in terms of the efficacy and safety were similar in both groups. ${ }^{47}$ Another study about the learning curve of POEM also showed that previous endoscopic treatment was one of the independent predictive factors of a longer procedure time. ${ }^{48}$ However, there were also several contrary results that showed no significant difference even in operation time, efficacy, and safety. ${ }^{49-51}$

POEM could also be used in the setting of recurrence or failure after previous surgical myotomy. The results of three studies examining the utility of POEM in patients who have undergone a previous surgical myotomy have been published. Zhou et $\mathrm{al}^{52}$ reported 12 patients, Onimaru et a ${ }^{11}$ reported 10 patients, and $\mathrm{Vi}_{1-}$ gneswaran et al ${ }^{53}$ reported 5 patients, whose symptoms recurred after Heller myotomy; these patients subsequently underwent salvage POEM. All these series showed acceptable feasibility, safety, and relatively high clinical efficacy in the range of $91.7 \%$ to $100 \%$. ${ }^{11,52,53}$

In conclusion, POEM in the setting of previous interventions seems to be equally safe and efficacious when performed by experts; however, it may be more technically challenging. Therefore, inexperienced POEM operators must be cautious while treating such cases.

\section{Sigmoid-shaped Esophagus in Achalasia}

Some advanced achalasia patients show progression to a sigmoid esophagus due to severe dilatation and subsequent tortuous angulation of their esophageal lumen. Severe sigmoid esophagus can markedly increase the procedural difficulty of POEM. Patients with severe esophageal stasis could show inflammation and fibrosis of the submucosa, hindering submucosal tunneling; severe angulations also make the direction of submucosal tunneling very puzzling. ${ }^{17}$ In our experience, the deepest possible submucosal tunneling could help maintain the correct aboral direction of the submucosal tunnel by ensuring the direction to be perpendicular to the circular muscle fibers. Although some experts reported good feasibility and efficacy of POEM even in these advanced patients, ${ }^{8,40}$ these cases seem to be particularly challenging and should be performed only by highly experienced operators.

\section{Spastic Esophageal Disorders}

Spastic esophageal disorders (SEDs) may include spastic achalasia (type III achalasia), distal esophageal spasm (diffuse esopha- geal spasm [DES]), and jackhammer esophagus. ${ }^{14}$ Although each of these disorders has a different pathophysiology, they share many similar clinical symptoms such as chest pain, regurgitation, and dysphagia. In terms of the coexistence of dysphagia and esophageal spasm, surgical myotomy is one of the best treatment options for SEDs. ${ }^{54}$ Similarly, POEM could also be applied for the treatment of these SEDs, and there have been multiple case reports that showed that POEM had excellent clinical efficacy for various SEDs, including jackhammer esophagus, DES, or Nutcracker esophagus. ${ }^{910,55-59}$ The results of an international multicenter study of POEM for SEDs were recently published. ${ }^{60}$ This study collected retrospective data of 9 patients with DES, 10 patients with jackhammer esophagus, and 54 patients with spastic achalasia from 11 centers. Overall, a clinical response was observed in 93\%, and the clinical response in each disease category was $100 \%$ in DES, $96.3 \%$ in spastic achalasia and $70 \%$ in jackhammer esophagus, which was significantly lower than that of other diseases. The jackhammer esophagus possibly may be a more difficult entity to treat with POEM when compared to both spastic achalasia and DES. The authors suggested the reason for the diminished response of POEM in jackhammer esophagus seems to be related to the extremely high contractility of the esophageal body; they suggested the value of concomitant bilateral (anterior and posterior) myotomy as a possible alternative for such patients. However, we think that the length of myotomy is still the most important factor for clinical success in jackhammer esophagus. POEM for SEDs generally involved long myotomy (mean length $=16 \mathrm{~cm}$ ), ${ }^{60}$ which was almost double of that used in conventional POEM, because patients with these SEDs frequently have chest pain often associated with spastic contraction of the esophageal body. ${ }^{61}$ When the patient has chest pain (common in DES, jackhammer esophagus, and nutcracker esophagus), which may be related to abnormal spastic contractions, the POEM operator should take care to ensure the length of the myotomy extends to the area of the most proximal spastic contraction. However, in some cases with long spastic contraction of the esophageal body, such a long myotomy length might still be insufficient, and the remnant proximal spastic segment may affect residual symptoms. In a previous case report, a woman with jackhammer esophagus was treated with POEM but presented with symptomatic recurrence after six months. The high resolution manometry showed a remnant spasm segment of the esophageal body proximal to the myotomy, and her symptoms could be resolved after endoscopic balloon dilation of the proximal spastic segment. ${ }^{55}$

The myotomy length should be decided on the basis of the patients' manometric, radiological, clinical, and endoscopic findings, 
especially in patients with SEDs. Although the accumulated data are not enough, POEM seems to be a very promising treatment option for patients with these SEDs.

\section{Future Perspective of Peroral Endoscopic Myotomy}

There have been numerous studies regarding the efficacy and application of POEM. It can be used to treat a variety of esophageal motility disorders including all types of achalasia, DES, and jackhammer esophagus. However, there is still ongoing discussion about the role of POEM in the management algorithm of achalasia, and where it stands in relation to balloon dilatation and surgical myotomy.

Further questions have arisen as POEM is being accepted widely. The questions include the ideal length of myotomy, the side to be cut, and if a full layer endoscopic myotomy or just division of the inner circular muscle should be performed. Further evaluation with longer observation is needed to evaluate these issues.

POEM has also brought tremendous attention to esophageal motility diseases, which includes the etiology of achalasia, ${ }^{62}$ carci- $^{-}$ nogenesis of the disease, ${ }^{63}$ and endoscopic diagnosis. ${ }^{64,65}$ The whole story regarding esophageal achalasia may be elucidated in the near future.

\section{Financial support: None.}

\section{Conflicts of interest: None.}

Author contributions: Young Hoon Youn and Hitomi Minami equally contributed to literature search and writing the manuscript; and Philip Wai Yan Chiu and Hyojin Park equally contributed to study idea and final revision of the manuscript.

\section{References}

1. Heller. Extramuköse Kardiaplastik beim chronischen Kardiospasmus mit dilatation des oesophagus. Mitt Grenzgeb Med Chir 1913;27:141-149.

2. Frimberger E, Kühner W, Kunert H, Ottenjann R. Results of treatment with the endoscope dilator in 11 patients with achalasia of the esophagus. Endoscopy 1981;13:173-175.

3. Eckardt VF, Aignherr C, Bernhard G. Predictors of outcome in patients with achalasia treated by pneumatic dilation. Gastroenterology 1992;103: 1732-1738.

4. Pasricha PJ, Ravich WJ, Kalloo AN. Botulinum toxin for achalasia. Lancet 1993;341:244-245.
5. Hoffman BJ, Knapple WL, Bhutani MS, Verne GN, Hawes RH. Treatment of achalasia by injection of botulinum toxin under endoscopic ultrasound guidance. Gastrointest Endosc 1997;45:77-79.

6. Giday SA, Kantsevoy SV, Kalloo AN. Principle and history of natural orifice translumenal endoscopic surgery (NOTES). Minim Invasive Ther Allied Technol 2006;15:373-377.

7. Ko CW, Kalloo AN. Per-oral transgastric abdominal surgery. Chin J Dig Dis 2006;7:67-70.

8. Inoue H, Minami H, Kobayashi Y, et al. Peroral endoscopic myotomy (POEM) for esophageal achalasia. Endoscopy 2010;42:265-271.

9. Minami H, Isomoto H, Yamaguchi N, et al. Peroral endoscopic myotomy (POEM) for diffuse esophageal spasm. Endoscopy 2014;46(suppl 1) UCTN:E79-E81.

10. Shiwaku H, Inoue H, Beppu R, et al. Successful treatment of diffuse esophageal spasm by peroral endoscopic myotomy. Gastrointest Endosc 2013;77:149-150.

11. Onimaru M, Inoue $\mathrm{H}$, Ikeda $\mathrm{H}$, et al. Peroral endoscopic myotomy is a viable option for failed surgical esophagocardiomyotomy instead of redo surgical Heller myotomy: a single center prospective study. J Am Coll Surg 2013;217:598-605

12. Minami $H$, Inoue $H$, Isomoto $H$, Urabe $S$, Nakao K. Clinical application of endoscopic ultrasonography for esophageal achalasia. Dig Endosc 2015;27(suppl 1):11-16.

13. Bredenoord AJ, Fox M, Kahrilas PJ, et al. Chicago classification criteria of esophageal motility disorders defined in high resolution esophageal pressure topography. Neurogastroenterol Motil 2012;24(suppl 1):57-65.

14. Kahrilas PJ, Bredenoord AJ, Fox M, et al. The Chicago classification of esophageal motility disorders, v3.0. Neurogastroenterol Motil 2015;27: 160-174.

15. Minami H, Inoue H, Haji A, et al. Per-oral endoscopic myotomy: emerging indications and evolving techniques. Dig Endosc 2015;27:175181.

16. Grimes KL, Inoue H, Onimaru M, et al. Double-scope per oral endoscopic myotomy (POEM): a prospective randomized controlled trial. Surg Endosc Published Online First: 15 Jul 2015. doi: 10.1007/s00464015-4396-2

17. Bechara R, Ikeda H, Inoue H. Peroral endoscopic myotomy: an evolving treatment for achalasia. Nat Rev Gastroenterol Hepatol 2015;12:410426.

18. Bhayani NH, Kurian AA, Dunst CM, Sharata AM, Rieder E, Swanstrom LL. A comparative study on comprehensive, objective outcomes of laparoscopic Heller myotomy with per-oral endoscopic myotomy (POEM) for achalasia. Ann Surg 2014;259:1098-1103.

19. Teitelbaum EN, Soper NJ, Santos BF, et al. Symptomatic and physiologic outcomes one year after peroral esophageal myotomy (POEM) for treatment of achalasia. Surg Endosc 2014;28:3359-3365.

20. Hungness ES, Teitelbaum EN, Santos BF, et al. Comparison of perioperative outcomes between peroral esophageal myotomy (POEM) and laparoscopic Heller myotomy. J Gastrointest Surg 2013;17:228-235.

21. Li QL, Chen WF, Zhou PH, et al. Peroral endoscopic myotomy for the treatment of achalasia: a clinical comparative study of endoscopic fullthickness and circular muscle myotomy. J Am Coll Surg 2013;217:442- 
451.

22. von Renteln D, Inoue H, Minami H, et al. Peroral endoscopic myotomy for the treatment of achalasia: a prospective single center study. Am J Gastroenterol 2012;107:411-417.

23. Lee BH, Shim KY, Hong SJ, et al. Peroral endoscopic myotomy for treatment of achalasia: initial results of a korean study. Clin Endosc 2013;46:161-167.

24. Chiu PW, Wu JC, Teoh AY, et al. Peroral endoscopic myotomy for treatment of achalasia: from bench to bedside (with video). Gastrointest Endosc 2013;77:29-38.

25. Chan SM, Wu JC, Teoh AY, et al. Comparison of early outcomes and quality of life after laparoscopic Heller's cardiomyotomy to peroral endoscopic myotomy for treatment of achalasia. Dig Endosc Published Online First: 24 Jun 2015. doi: 10.1111/den.12507.

26. Ling TS, Guo HM, Yang T, Peng CY, Zou XP, Shi RH. Effectiveness of peroral endoscopic myotomy in the treatment of achalasia: a pilot trial in Chinese Han population with a minimum of one-year follow-up. J Dig Dis 2014;15:352-358.

27. Ujiki MB, Yetasook AK, Zapf M, Linn JG, Carbray JM, Denham W. Peroral endoscopic myotomy: a short-term comparison with the standard laparoscopic approach. Surgery 2013;154:893-897; discussion 897-900.

28. Ghoshal UC, Kumar S, Saraswat VA, Aggarwal R, Misra A, Choudhuri G. Long-term follow-up after pneumatic dilation for achalasia cardia: factors associated with treatment failure and recurrence. Am J Gastroenterol 2004;99:2304-2310.

29. Andersson M, Lundell L, Kostic S, et al. Evaluation of the response to treatment in patients with idiopathic achalasia by the timed barium esophagogram: results from a randomized clinical trial. Dis Esophagus 2009;22:264-273.

30. Nicodème F, de Ruigh A, Xiao Y, et al. A comparison of symptom severity and bolus retention with Chicago classification esophageal pressure topography metrics in patients with achalasia. Clin Gastroenterol Hepatol 2013;11:131-137.

31. Pandolfino JE, de Ruigh A, Nicodème F, Xiao Y, Boris L, Kahrilas PJ. Distensibility of the esophagogastric junction assessed with the functional lumen imaging probe (FLIP) in achalasia patients. Neurogastroenterol Motil 2013;25:496-501.

32. Patel K, Abbassi-Ghadi N, Markar S, Kumar S, Jethwa P, Zaninotto G. Peroral endoscopic myotomy for the treatment of esophageal achalasia: systematic review and pooled analysis. Dis Esophagus Published Online First: 14 Jul 2015. doi: 10.1111/dote.12387.

33. Rohof WO, Hirsch DP, Kessing BF, Boeckxstaens GE. Efficacy of treatment for patients with achalasia depends on the distensibility of the esophagogastric junction. Gastroenterology 2012;143:328-335.

34. Teitelbaum EN, Sternbach JM, El Khoury R, et al. The effect of incremental distal gastric myotomy lengths on EGJ distensibility during POEM for achalasia. Surg Endosc Published Online First: 2015. doi:10.1007/s00464-015-4269-8.

35. Teitelbaum EN, Boris L, Arafat FO, et al. Comparison of esophagogastric junction distensibility changes during POEM and Heller myotomy using intraoperative FLIP. Surg Endosc 2013;27:4547-4555.

36. Sharata AM, Dunst CM, Pescarus R, et al. Peroral endoscopic myotomy
(POEM) for esophageal primary motility disorders: analysis of 100 consecutive patients. J Gastrointest Surg 2015;19:161-170; discussion 170.

37. Yao S, Linghu E. Peroral endoscopic myotomy can improve esophageal motility in patients with achalasia from a large sample self-control research (66 patients). PLoS One 2015;10:e0125942.

38. Inoue $\mathrm{H}$, Sato $\mathrm{H}$, Ikeda $\mathrm{H}$, et al. Per-oral endoscopic myotomy: a series of 500 patients. J Am Coll Surg 2015;221:256-264.

39. Von Renteln D, Fuchs KH, Fockens P, et al. Peroral endoscopic myotomy for the treatment of achalasia: an international prospective multicenter study. Gastroenterology 2013;145:309-311, e1-e3.

40. Hu JW, Li QL, Zhou PH, et al. Peroral endoscopic myotomy for advanced achalasia with sigmoid-shaped esophagus: long-term outcomes from a prospective, single-center study. Surg Endosc 2015;29:2841-2850.

41. Chen WF, Li QL, Zhou PH, et al. Long-term outcomes of peroral endoscopic myotomy for achalasia in pediatric patients: a prospective, singlecenter study. Gastrointest Endosc 2015;81:91-100.

42. Minami H, Isomoto H, Yamaguchi N, et al. Peroral endoscopic myotomy for esophageal achalasia: clinical impact of 28 cases. Dig Endosc 2014;26:43-51.

43. Ren Z, Zhong Y, Zhou P, et al. Perioperative management and treatment for complications during and after peroral endoscopic myotomy (POEM) for esophageal achalasia (EA) (data from 119 cases). Surg Endosc 2012;26:3267-3272.

44. Yang S, Zeng MS, Zhang ZY, Zhang HL, Liang L, Zhang XW. Pneumomediastinum and pneumoperitoneum on computed tomography after peroral endoscopic myotomy (POEM): postoperative changes or complications? Acta Radiol 2015;56:1216-1221.

45. Maselli R, Inoue $\mathrm{H}$, Misawa M, et al. Peroral endoscopic myotomy (POEM) in a 3-year-old girl with severe growth retardation, achalasia, and Down syndrome. Endoscopy 2012;44(suppl 2) UCTN:E285-E287.

46. Familiari P, Marchese M, Gigante G, et al. Peroral endoscopic myotomy for the treatment of achalasia in children. J Pediatr Gastroenterol Nutr 2013;57:794-797.

47. Ling T, Guo H, Zou X. Effect of peroral endoscopic myotomy in achalasia patients with failure of prior pneumatic dilation: a prospective casecontrol study. J Gastroenterol Hepatol 2014;29:1609-1613.

48. Teitelbaum EN, Soper NJ, Arafat FO, et al. Analysis of a learning curve and predictors of intraoperative difficulty for peroral esophageal myotomy (POEM). J Gastrointest Surg 2014;18:92-98; discussion 98-99.

49. Sharata A, Kurian AA, Dunst CM, Bhayani NH, Reavis KM, Swanström LL. Peroral endoscopic myotomy (POEM) is safe and effective in the setting of prior endoscopic intervention. J Gastrointest Surg 2013;17:1188-1192.

50. Orenstein SB, Raigani S, Wu YV, et al. Peroral endoscopic myotomy (POEM) leads to similar results in patients with and without prior endoscopic or surgical therapy. Surg Endosc 2015;29:1064-1070.

51. Jones EL, Meara MP, Pittman MR, Hazey JW, Perry KA. Prior treatment does not influence the performance or early outcome of per-oral endoscopic myotomy for achalasia. Surg Endosc Published Online First: 27 Jun 2015. doi: 10.1007/s00464-015-4339-y.

52. Zhou PH, Li QL, Yao LQ, et al. Peroral endoscopic remyotomy for failed Heller myotomy: a prospective single-center study. Endoscopy 
2013;45:161-166

53. Vigneswaran Y, Yetasook AK, Zhao JC, Denham W, Linn JG, Ujiki MB. Peroral endoscopic myotomy (POEM): feasible as reoperation following Heller myotomy. J Gastrointest Surg 2014;18:1071-1076.

54. Patti MG, Pellegrini CA, Arcerito M, Tong J, Mulvihill SJ, Way LW. Comparison of medical and minimally invasive surgical therapy for primary esophageal motility disorders. Arch Surg 1995;130:609-615; discussion 615-616.

55. Kandulski A, Fuchs KH, Weigt J, Malfertheiner P. Jackhammer esophagus: high-resolution manometry and therapeutic approach using peroral endoscopic myotomy (POEM). Dis Esophagus Published Online First: 27 Jan 2014. doi: 10.1111/dote.12182.

56. Kumbhari V, Tieu AH, Onimaru M, et al. Peroral endoscopic myotomy (POEM) vs laparoscopic Heller myotomy (LHM) for the treatment of Type III achalasia in 75 patients: a multicenter comparative study. Endosc Int Open 2015;3:E195-E201.

57. Louis H, Covas A, Coppens E, Devière J. Distal esophageal spasm treated by peroral endoscopic myotomy. Am J Gastroenterol 2012;107:19261927.

58. Khashab MA, Saxena P, Kumbhari V, et al. Peroral endoscopic myotomy as a platform for the treatment of spastic esophageal disorders refractory to medical therapy (with video). Gastrointest Endosc 2014;79:136-139.

59. Ko WJ, Lee BM, Park WY, et al. Jackhammer esophagus treated by a peroral endoscopic myotomy. Korean J Gastroenterol 2014;64:370-374.

60. Khashab MA, Messallam AA, Onimaru M, et al. International multicenter experience with peroral endoscopic myotomy for the treatment of spastic esophageal disorders refractory to medical therapy (with video). Gastrointest Endosc 2015;81:1170-1177.

61. Balaban DH, Yamamoto Y, Liu J, et al. Sustained esophageal contraction: a marker of esophageal chest pain identified by intraluminal ultrasonography. Gastroenterology 1999;116:29-37.

62. Sumiyama K, Tajiri H, Kato F, et al. Pilot study for in vivo cellular imaging of the muscularis propria and ex vivo molecular imaging of myenteric neurons (with video). Gastrointest Endosc 2009;69:1129-1134.

63. Minami H, Yamaguchi N, Matsushima K, et al. Improvement of endocytoscopic findings after per oral endoscopic myotomy (POEM) in esophageal achalasia; does POEM reduce the risk of developing esophageal carcinoma? Per oral endoscopic myotomy, endocytoscopy and carcinogenesis. BMC Gastroenterol 2013;13:22.

64. Iwakiri K, Hoshihara Y, Kawami N, et al. The appearance of rosettelike esophageal folds ("esophageal rosette") in the lower esophagus after a deep inspiration is a characteristic endoscopic finding of primary achalasia. J Gastroenterol 2010;45:422-425.

65. Minami H, Isomoto $\mathrm{H}$, Miuma $\mathrm{S}$, et al. New endoscopic indicator of esophageal achalasia: "pinstripe pattern". PLoS One 2015;10:e0101833. 